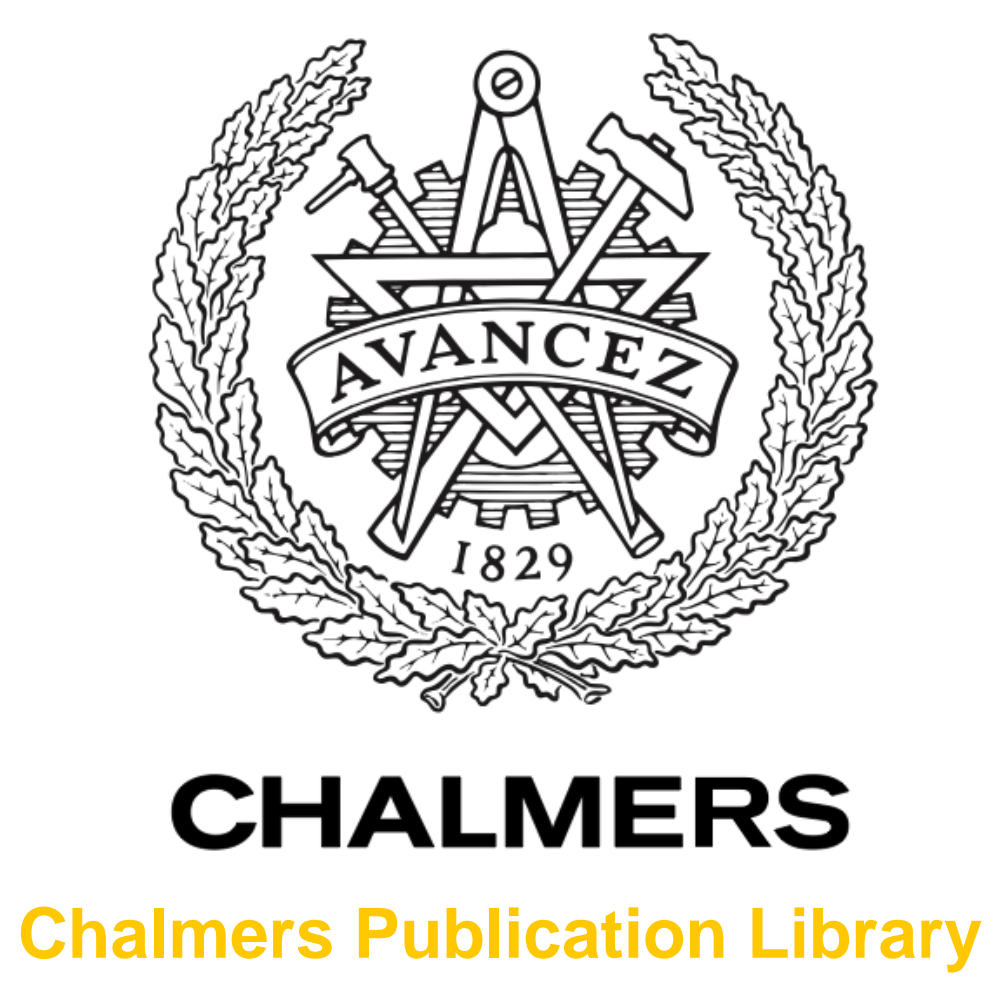

\title{
Decay of Bacteroidales Genetic Markers in Relation to Traditional Fecal Indicators for Water Quality Modeling of Drinking Water Sources
}

This document has been downloaded from Chalmers Publication Library (CPL). It is the author's version of a work that was accepted for publication in:

Environmental Science and Technology (ISSN: 0013-936X)

Citation for the published paper:

Sokolova, E. ; Åström, J. ; Pettersson, T. (2012) "Decay of Bacteroidales Genetic Markers in Relation to Traditional Fecal Indicators for Water Quality Modeling of Drinking Water

Sources". Environmental Science and Technology, vol. 46(2), pp. 892-900.

http://dx.doi.org/10.1021/es2024498

Downloaded from: http://publications.lib.chalmers.se/publication/154413

Notice: Changes introduced as a result of publishing processes such as copy-editing and formatting may not be reflected in this document. For a definitive version of this work, please refer to the published source. Please note that access to the published version might require a subscription. 
Decay of Bacteroidales genetic markers in relation to traditional fecal indicators for water quality modeling of drinking water sources

Ekaterina Sokolova $^{\mathrm{a}, *}$, Johan Åström ${ }^{\mathrm{a}}$, Thomas J. R. Pettersson ${ }^{\mathrm{a}}$, Olof Bergstedt ${ }^{\mathrm{b}}$ and Malte Hermansson ${ }^{\mathrm{c}}$.

${ }^{\mathrm{a}}$ Water Environment Technology, Chalmers University of Technology, SE-412 96

Gothenburg, Sweden. *Corresponding author. Phone: +46 31 7721929, Fax: +46 317722128 , E-mail address: ekaterina.sokolova@chalmers.se

${ }^{\mathrm{b}}$ Gothenburg Water, City of Gothenburg, Box 123, SE-424 23 Angered, Sweden.

${ }^{\mathrm{c}}$ Department of Cell and Molecular Biology, Microbiology, University of Gothenburg, SE40530 Gothenburg, Sweden. 


\begin{abstract}
The implementation of microbial fecal source tracking (MST) methods in drinking water management is limited by the lack of knowledge on the transport and decay of host-specific genetic markers in water sources. To address these limitations, the decay and transport of human (BacH) and ruminant (BacR) fecal Bacteroidales 16S rRNA genetic markers in a drinking water source (Lake Rådasjön in Sweden) were simulated using a microbiological model coupled to a three-dimensional hydrodynamic model. The microbiological model was calibrated using data from outdoor microcosm trials performed in March, August and November 2010 to determine the decay of BacH and BacR markers in relation to traditional fecal indicators. The microcosm trials indicated that the persistence of $\mathrm{BacH}$ and BacR in the microcosms was not significantly different from the persistence of traditional fecal indicators. The modeling of BacH and BacR transport within the lake illustrated that the highest levels of genetic markers at the raw water intakes were associated with human fecal sources (on-site sewers and emergency sewer overflow). This novel modeling approach improves the interpretation of MST data, especially when fecal pollution from the same host group is released into the water source from different sites in the catchment.
\end{abstract}




\section{Introduction}

The fecal pollution of water sources is a common cause of waterborne disease outbreaks. ${ }^{1}$ Detecting the presence of fecal pollution in the water source forms the basis for preventing waterborne disease outbreaks. While traditional fecal indicators, such as total coliforms, $E$. coli and intestinal enterococci, provide a general indication of fecal pollution, human and ruminant-specific Bacteroidales assays can be used for microbial source tracking (MST) to indicate the human or ruminant origin of fecal pollution. ${ }^{2}$ Several Bacteroidales assays have been proposed for the identification of host-specific fecal matter from humans and cattle..$^{3-9}$ The Bacteroidales marker assays have been used to determine the health risks in different environments. ${ }^{10-12}$ Furthermore, the correlation between the presence of host-specific Bacteroidales markers and the presence of various pathogens has been examined in order to better understand the health risks. ${ }^{13-15}$ However, the application of this technique in surface water management related to microbial pollution is limited by several research gaps, among which is the need for further knowledge on genetic marker host-specificity, correlation with traditional fecal indicators and pathogens, and decay in the environment. ${ }^{2,16}$

In a catchment, there are often several human and ruminant fecal pollution sources, which are located at various distances from the water intake. While the detection of Bacteroidales human and ruminant genetic markers at the water intake can provide information on the human or ruminant origin of fecal pollution, it cannot provide information on the contribution from each specific pollution site. In urbanized catchments, discharges of human fecal matter often come from multiple point sources, such as combined sewer overflows, on-site sewer systems and wastewater treatment plants. It should be noted that wastewater effluents have been pointed out as major pollution sources involved in the large Cryptosporidium outbreak in Milwaukee, USA (1993), ${ }^{1}$ the Giardia outbreak in Bergen, Norway (2004), ${ }^{17}$ and several waterborne disease outbreaks in Sweden. ${ }^{1}$ In rural catchments, fecal matter from ruminants may be sporadically released by surface runoff from manure-fertilized agricultural areas and cattle grazing areas. However, the identification of the quantitatively most important pollution source(s) is often the main goal of practical source tracking studies. ${ }^{16}$

The detected genetic marker levels from different sources at a given location are dependent on the transport within the water body and decay processes. Therefore, transport and decay processes in the water source need to be considered in the interpretation of MST data to provide the basis for remediation measures. In order to describe the transport and decay of genetic markers released from different sources in a water body, a coupled hydrodynamic and microbiological modeling approach can be used. This approach has previously been applied to simulate the fate and transport of traditional fecal indicators. ${ }^{18-20}$

In order to accurately simulate the fate and transport of Bacteroidales genetic markers in the water source, the research gap regarding their decay needs to be addressed. The decay of traditional fecal indicators has been extensively studied during the past decades. ${ }^{21-24}$ However, MST based on fecal Bacteroidales markers is a fairly new approach and few experiments have been carried out to determine their decay. ${ }^{25-28}$ The decay of these markers, as well as of fecal indicators in general, is expected to be site-specific and to depend on environmental conditions, such as temperature, exposure to sunlight, the presence of indigenous microorganisms, and the physical and chemical water properties. ${ }^{25-27}$ Therefore, the decay of Bacteroidales markers in the water source in relation to traditional fecal indicators needs to be determined for different seasons of the year. ${ }^{28}$ Consequently, more experimental data are needed to expand the knowledge on the decay of Bacteroidales genetic markers. 
In this study, we have determined the decay of Bacteroidales genetic markers in water from a surface drinking water source (Lake Rådasjön in Sweden) in relation to the decay of traditional fecal indicators, based on outdoor microcosm trials, performed in March, August and November of 2010. The data on the decay of Bacteroidales genetic markers were then used to simulate the fate and transport of the Bacteroidales markers in Lake Rådasjön. 


\section{Material and Methods}

\section{Microcosm experiment arrangement}

Outdoor microcosm trials were conducted during two-week periods in March, August and November 2010 in order to capture the varying light and temperature conditions. Two microcosms were constructed, one exposed to natural light (light microcosm) and another protected from light (dark microcosm), to resemble the conditions on the surface and at the bottom of the lake. Microcosms were constructed in aquaria filled with raw water from Lake Rådasjön (Gothenburg, Sweden) and inoculated with untreated wastewater and bovine fecal matter. Both aquaria (25 L each) were made of transparent colorless glass. The dark microcosm aquarium was covered by aluminum foil and a lid of opaque material to prevent sunlight and rain penetration. The light microcosm aquarium was protected from rain by transparent film that transmits UVA/B radiation (ultraviolet radiation in the wavelength range $280-400 \mathrm{~nm}$ ). The UVA/B transmission of the film exceeded $90 \%$ during all trials, as measured with a UVA/B light meter (UVA/B light meter 850009, Sper Scientific, AZ). To provide aerobic conditions, continuous circulation and mixing in the microcosms, a circulation and air pump was installed in each aquarium. Both aquaria were placed in a large tank with water (approximately $150 \mathrm{~L}$ ), where warming (HETO Ultrathermostat, Birkerod, Denmark) and cooling (FT200 Immersion Cooler, JULABO Labortechnik, Seelbach, Germany) equipment were installed to regulate the water temperature in the microcosms. The experimental arrangement was placed at the Lackarebäck drinking water treatment plant, in the vicinity of Lake Rådasjön.

The lake water, untreated wastewater and bovine fecal matter were collected within $5 \mathrm{~h}$ before the start of each trial and kept cooled. Untreated wastewater was collected from a sewer pumping station, from which emergency overflows to the lake can occur (Figure 1, site P). Ten samples of bovine fecal matter were collected from ten animals of different age and sex. The inocula volumes for the microcosms were chosen to provide high initial concentrations of all indicators. ${ }^{28}$ Bovine fecal slurry was prepared by mixing $60 \mathrm{~g}$ of fecal matter $(6 \mathrm{~g}$ from every sample) and $300 \mathrm{~mL}$ of sterile deionized water using a BagMixer 100 (MiniMix, InterScience, France) for 30 seconds. Water from Lake Rådasjön was collected from a landing stage (20 m distance from the shore) at $0.5 \mathrm{~m}$ depth (Figure 1, site V). Each microcosm was created by adding $2.5 \mathrm{~L}$ of untreated wastewater and $100 \mathrm{~mL}$ of fecal slurry to the aquarium, followed by filling up with lake water (approximately $20 \mathrm{~L}$ ). Then the water in each aquarium was circulated for 20 minutes before the first sample was taken.

\section{Sampling and analyses}

The three decay trials commenced on 15 March, 16 August and 15 November 2010 and lasted 14 days each. One sample was taken from each microcosm at around noon on days $0,1,2$, 3, 4, 7, 10 and 14. In March, two additional samples were taken on day 1 and day 7 to determine the variability of human and ruminant Bacteroidales marker concentrations in each microcosm. A sample of the lake water prior to inoculation was taken before each trial.

The samples were analyzed for total coliforms, E. coli, intestinal enterococci, somatic coliphages and Bacteroidales markers. Total coliforms and E. coli bacteria were analyzed within $4 \mathrm{~h}$ after sampling by Colilert ${ }^{\mathrm{TM}}$ Quantitray method (IDEXX Laboratories, Inc., ME, USA) following the MPN (Most Probable Number) method. Intestinal enterococci were 
analyzed within $4 \mathrm{~h}$ after sampling according to the membrane filtration method. ${ }^{29}$ Somatic coliphages were analyzed within $48 \mathrm{~h}$ after sampling following the plaque assay method. ${ }^{30}$

For the analysis of human (BacH) and ruminant (BacR) Bacteroidales 16S rRNA markers samples from the microcosms $(100 \mathrm{~mL})$ were filtered onto Isopore $0.2 \mu \mathrm{m}$ polycarbonate membrane filters (Millipore ${ }^{\mathrm{TM}}$, Bedford, MA, USA) within $3 \mathrm{~h}$ after sampling using vacuum pressure. The filters were frozen at $-20^{\circ} \mathrm{C}$ for preservation until the DNA-extraction, which was performed within three weeks. ${ }^{31}$ Negative controls for each extraction round were performed to exclude the contamination of DNA during the processing. The qPCR analyses were performed as described in previous studies and using the same primers and probes. ${ }^{3-4}$ Briefly, the qPCR analyses were performed on an iCycler iQ 5 (Bio-Rad, Hercules, CA, USA). Plasmid standards for the qPCR analyses of BacH and BacR were diluted tenfold (minimum five dilution steps) in an unspecific DNA background (5 $\mathrm{ng} / \mu \mathrm{l}$ poly d(I-C) solution) and used for the quantification in all qPCR runs. Since the Bacteroidales cells carrying these markers are not cultivated and copy numbers cannot be directly related to cell numbers, values were reported as marker equivalents (ME) ${ }^{3-4} \mathrm{ME}$ values signify the copy number after possible DNA losses during the extraction. ${ }^{3-4}$ Therefore, care was taken to treat all samples equally. In order to determine the concentration of ME, quantification was performed at the annealing temperatures: $61^{\circ} \mathrm{C}$ for $\mathrm{BacH}$ and $60^{\circ} \mathrm{C}$ for $\mathrm{BacR} .^{3-4}$ All reactions were performed in duplicate and on several dilutions of each sample. For each sample the dilution that resulted in the highest qPCR result was selected for quantification. . $^{3-4}$

The water temperature in the microcosms was monitored at 10 minute intervals during each experimental period using temperature loggers (Thermistors, type 10k NTC, Gemini Data Loggers Ltd., UK) placed in each microcosm. Time series of the total solar radiation in Gothenburg during each experimental period were obtained from the official environmental measurements performed by the City of Gothenburg at a monitoring station located approximately $7 \mathrm{~km}$ from the experimental site. In addition, the UVA/B radiation at the experimental site was repeatedly measured during the trials in August and November using the aforementioned UVA/B light meter. The dissolved oxygen concentration in the microcosms was measured in the beginning of each trial using a Multiline instrument (WTW Multiline instrument P4).

\section{Experimental data analysis}

Linear regression was applied to the natural logarithm transformed indicator measurements to derive the decay rates $(k){ }^{22,32}$ To enable comparisons with other studies, the persistence of the fecal indicators was described by the time for a $90 \%$ reduction of fecal indicator concentrations ( $\mathrm{T}_{90}$-values) calculated according to Equation 1:

$$
T_{90}=\frac{\ln (0.1)}{k}
$$

The statistical analysis of the experimental data was performed using t-tests and linear regression analyses in PASW Statistics 18.0 (SPSS Inc.).

\section{Hydrodynamic and microbiological modeling}

Lake Rådasjön (Figure 1) is located on the west coast of Sweden and constitutes the main water source for the city of Mölndal (60 000 consumers) and a reserve water source for the city of Gothenburg (500 000 consumers). The area of the lake is approximately $2.0 \mathrm{~km}^{2}$ and 
the maximum water depth is $23 \mathrm{~m}$. The catchment area of the lake is $268 \mathrm{~km}^{2}$ and the main inflow to the lake is the river Mölndalsån with a water flow from 1 to $20 \mathrm{~m}^{3} / \mathrm{s}$. The raw water intakes for the city of Mölndal (15 m depth) and the city of Gothenburg ( $8 \mathrm{~m}$ depth) are located in the northwestern part of the lake (Figure 1).

Human fecal pollution in Lake Rådasjön may originate from on-site sewers located to the north of the lake. The on-site sewers release partly treated effluents into streams that enter the lake (Figure 1, sites 3 and 7). Another source of human fecal pollution is an emergency discharge outlet of a pumping station in a separate sewer system located to the south of the lake (Figure 1, site P). Discharges of untreated wastewater from this source occur several times a year during periods of heavy rainfall after stormwater intrusion into the sewer network. Furthermore, animal fecal pollution can be released from a cattle grazing area on the eastern side of the lake (Figure 1, site 17).

To evaluate the fate and transport of BacH and BacR markers released from the major human (sites 3, 7 and P) and ruminant (site 17) pollution sites, several scenarios were simulated using a coupled hydrodynamic and microbiological model. The simulations were performed for March, August and November conditions, with southwest and southeast winds of a constant speed of $3 \mathrm{~m} / \mathrm{s}$. These wind conditions were chosen since southwest winds are predominant in Gothenburg, while southeast winds are expected to cause the most rapid transport of microbial pollution to the raw water intakes. The assumptions regarding the discharges from fecal pollution sources were: continuous constant discharges from the on-site sewers (sites 3 and 7), pulse discharge for $72 \mathrm{~h}$ from the emergency sewer overflow (site $\mathrm{P}$ ) and pulse discharge for $48 \mathrm{~h}$ from the stream running through the cattle grazing area (site 17). The concentrations of BacH and BacR markers in the discharges from these sources were determined based on the monitoring data (Table 1). Simulations were carried out for a normal case and a worst case scenario, based on the median and maximum BacH and BacR concentrations measured in the discharge from each pollution site (Table 1).

The water flows in Lake Rådasjön were simulated using a three-dimensional time-dependent hydrodynamic model MIKE 3 FM based on the numerical solution of three-dimensional incompressible Reynolds averaged Navier-Stokes equations using Boussinesq and hydrostatic assumptions. ${ }^{33}$ The modeling domain was approximated with prisms (triangles in horizontal plane) using a flexible mesh approach. The length of the triangle sides varies from approximately 40 to $80 \mathrm{~m}$ and was adjusted to describe the coastline and bathymetry. Vertically, the lake was divided into 27 layers. More information about the hydrodynamic model and approximation of the modeling domain can be found in the Supporting Information.

In order to simulate the fate and transport of the BacH and BacR markers in the lake a microbiological model ECO Lab ${ }^{34}$ was used. The microbiological model utilizes the flow fields from the hydrodynamic model and accounts for microbial decay. The decay of the BacH and BacR markers was described in the microbiological model according to Equation 2, which is a slight modification of a decay model that was proposed by Mancini ${ }^{35}$ to describe the decay of coliforms in natural waters. The coefficients in Equation 2 were determined based on the results of the microcosm experiment using linear regression.

$\frac{d C}{d t}=-k_{0} \cdot \theta_{S}^{\text {Sal }} \cdot \theta_{I}^{\text {Int }} \cdot \theta_{T}^{(\text {Temp-20) }} \cdot C$ 
where $t$ is time, $C$ is a fecal indicator concentration, $k_{0}(1 /$ day $)$ is the decay rate at $20^{\circ} \mathrm{C}$ for a salinity of $0 \%$ and darkness; $\theta_{\mathrm{s}}$ is the salinity coefficient for the decay rate; Sal (\%) is the salinity; $\theta_{\mathrm{I}}$ is the light coefficient; Int $\left(\mathrm{kW} / \mathrm{m}^{2}\right)$ is the light intensity integrated over depth; $\theta_{\mathrm{T}}$ is the temperature coefficient for the decay rate; $\operatorname{Temp}\left({ }^{\circ} \mathrm{C}\right)$ is the water temperature.

To evaluate the source-specific contribution to the total concentrations at the raw water intakes, the Bacteroidales markers released from different sources were simulated as separate variables. 


\section{Results}

The background concentrations of $\mathrm{BacH}$, BacR, total coliforms and E. coli in the lake water prior to inoculation constituted less than $0.05 \%$ of the initial concentrations in the microcosms in all trials (Table S2). The background concentrations of intestinal enterococci and somatic coliphages in the lake water constituted less than $2 \%$ of the initial concentrations in the microcosms in all trials, with exception of the November trial, when the background concentration of somatic coliphages in the lake water constituted 22 and $40 \%$ of the initial concentrations in the dark and light microcosms, respectively (Table S2). The mean water temperature in the microcosms was around 5, 20 and $6{ }^{\circ} \mathrm{C}$ in March, August and November, respectively; the mean solar radiation was 74, 127 and $22 \mathrm{~W} / \mathrm{m}^{2}$ in March, August and November, respectively (Table S3). The dissolved oxygen concentration in the microcosms exceeded $91 \%$ of the saturated dissolved oxygen concentration in all trials (Table S4).

\section{Decay of fecal indicators}

The decay of fecal indicators including $\mathrm{BacH}$ and $\mathrm{BacR}$ varied between different seasons (Figure 2). Statistical comparisons indicated that the persistence of fecal indicators was significantly lower in August than in March and November (paired t-test, $\mathrm{p}<0.05$ ), while no statistically significant differences in the persistence of fecal indicators were observed between March and November (paired t-test, $\mathrm{p}>0.05$ ). Regression analyses indicated that water temperature (mean, maximum and minimum values, Table S3) had a statistically significant effect on the persistence of fecal indicators $(\mathrm{p}<0.01)$. Statistical comparisons indicated that fecal indicators in the light and dark microcosms did not persist in a significantly different manner (paired samples t-test $\mathrm{p}>0.05$ ). The persistence of BacH and BacR was not significantly different from the persistence of other indicators (paired samples t-test, $\mathrm{p}>0.05$ ).

The most rapid decay of BacH and BacR was observed in August (Table 2). During the first week of the August trial, a rapid reduction of BacH and BacR was documented; however, low levels of $\mathrm{BacH}$ in the light microcosm and BacR in the dark microcosm were observed until day 14 (Figure 2C and 2D). The highest persistence of BacR and an increase of BacH concentrations were observed in November (Table 2, Figure 2E and 2F). The highest initial concentrations in the microcosms were observed for BacH and BacR, followed by total coliforms, E. coli, intestinal enterococci and somatic coliphages, respectively (Table 2).

The coefficients for Equation 2 were estimated using the experimental data and satisfactory $\mathrm{R}^{2}$-values were obtained ( 0.68 and 0.84 for BacH and BacR respectively). Since no statistically significant differences between the persistence of Bacteroidales genetic markers in light and dark microcosms were identified (paired samples t-test, $\mathrm{p}>0.05$ ) the light coefficient $\left(\theta_{\mathrm{I}}\right)$ in Equation 2 was set equal to 1 . The salinity coefficient $\left(\theta_{\mathrm{s}}\right)$ in Equation 2 was also set equal to 1 , since fresh water was used in the microcosms. Temperature $\left(\theta_{\mathrm{T}}\right)$ and $k_{0}$ coefficients were estimated to be 1.09 and 1.02, respectively, for $\mathrm{BacH}$; and 1.10 and 1.16, respectively, for BacR.

\section{Modeling}

The modeling results (Figure 3) indicated that Bacteroidales markers released from the fecal sources around the lake can reach the raw water intakes at varying concentrations depending on the season and the wind direction. For all sources, the highest concentrations at the raw 
water intakes were found in the simulations of March conditions, while the lowest concentrations were found in the simulations of August conditions. In fact, according to the simulations, concentrations at the $15 \mathrm{~m}$ intake under August conditions were generally below $50 \mathrm{ME} / 100 \mathrm{~mL}$.

Moreover, in the majority of the simulated scenarios the concentration at the $15 \mathrm{~m}$ intake was found to be lower than the concentration at the $8 \mathrm{~m}$ intake, except for pollution from the emergency overflow (site P) under March conditions. In general, southeast winds caused higher concentrations at the raw water intakes than southwest winds (Figure 3). The simulated scenarios indicated that the on-site sewers (site 3) provided the largest contribution to the Bacteroidales concentrations at the raw water intakes, followed by the emergency sewer overflow, the on-site sewers (site 7) and the cattle grazing area. 


\section{Discussion}

\section{Decay of Bacteroidales genetic markers}

The initial concentrations of $\mathrm{BacH}$ and $\mathrm{BacR}$ in the microcosms generally exceeded the initial concentrations of the other fecal indicators by several orders of magnitude (Table 2), which supports the utility of these markers for tracking the sources of highly diluted fecal matter in water bodies. The persistence of $\mathrm{BacH}$ and BacR in the microcosms was not significantly different from the persistence of the traditional fecal indicators. In the November trial, the $\mathrm{BacH}$ concentrations were higher than the initial concentrations in the microcosms on some occasions (Figure 2E and 2F), but an overall decrease of the concentrations was observed.

During the microcosm trials, the decay of BacH and BacR, as well as of the other fecal indicators, was fastest in the August trial, when the highest water temperatures in the microcosms were observed (Table 2). In the August trial concentrations of several indicators rapidly became undetectable (Figure 2C and 2D). This relation between high temperature and high decay rates is commonly reported for fecal indicators and pathogens. ${ }^{24,35-36}$ Earlier studies on Bacteroidales marker decay ${ }^{25-27,37}$ confirm the temperature dependence observed in the present study.

Moreover, the results of the microcosm experiment indicated that the decay of BacH and BacR, as well as of the other fecal indicators, was not dependent on the exposure to sunlight. This is consistent with several earlier studies on the persistence of Bacteroidales genetic markers. ${ }^{26,28,38-39}$ Nevertheless, sunlight effects are likely to be system or even site-specific, as illustrated in a previous field study, where human-specific Bacteroidales markers decayed more rapidly in the microcosm exposed to sunlight in comparison to dark conditions. ${ }^{40}$

The main mechanism of BacH and BacR decay is probably the destruction of the cell by predation or phage lysis. Predation and virus attacks are the main mechanisms of mortality of Bacteroidales cells, as indeed of all bacteria in aquatic environments. ${ }^{41}$ When cells are phagocytized or lysed by bacteriophages, DNA is released. Although free DNA can persist for a very long time in cold hypolimnion lake water, ${ }^{42}$ the $\mathrm{BacH}$ and BacR assays involve a filtration step and only cells or DNA bound to particles are measured. In several earlier microcosm studies ${ }^{39-40,43}$ it was reported that reduced predation resulted in longer Bacteroidales marker persistence.

In order to be properly used for water quality regulations and water quality modeling, fecal indicators should ultimately resemble the behavior and decay of human pathogens. The persistence of BacH and BacR measured in this study equals or exceeds the reported persistence of bacterial (Campylobacter) and viral pathogens (calicivirus), but is below the reported persistence of Cryptosporidium. ${ }^{36,43-44}$ This corresponds with the conclusions drawn by Walters and Field ${ }^{28}$ from their evaluation of other human and ruminant Bacteroidales markers.

\section{Fate and transport of Bacteroidales genetic markers in a water source}

Based on the experimental data, the decay of fecal Bacteroidales markers was described as a function of temperature with satisfactory $\mathrm{R}^{2}$-values, and integrated into the hydrodynamic model of the drinking water source. The coupled hydrodynamic and microbiological 
modeling of Lake Rådasjön demonstrated that the concentrations of BacH and BacR markers at the raw water intakes depended strongly on the concentration of genetic markers in the microbial discharges to the lake, the season as well as hydrodynamic and wind conditions. The modeling results indicated that (i) BacH and BacR markers released from the studied pollution sources can be expected to reach the raw water intakes; (ii) the concentrations of $\mathrm{BacH}$ and BacR at the raw water intakes can be expected to be the highest under early spring conditions and the lowest under summer conditions. The fact that the lowest levels of genetic markers at the raw water intakes were found in the simulations of August conditions can be explained by the high water temperature and, therefore, a relatively rapid decay. Furthermore, the temperature stratification of the lake in August prevents the transport of genetic markers to the deeper levels of the lake and protects the $15 \mathrm{~m}$ intake in particular. Results from the hydrodynamic modeling indicated that under the conditions of summer stratification the highest impact was related to on-site sewer discharges from site 3 . The model illustrated that the highest levels of genetic markers at the raw water intakes were associated with human sources of fecal pollution (Figure 3), thus suggesting that the focus for remediation measures should be on human sources in the area, primarily on the discharges from on-site sewers located in the vicinity of the raw water intakes (site 3) and on the emergency sewer overflow.

To evaluate the performance of the model, the model output was compared to the measured concentrations. The BacH and BacR concentrations measured in Lake Rådasjön at the $15 \mathrm{~m}$ water intake in 2008 and 2009 and at site V (Figure 1) in March, August and November 2010 were compared to the model output regarding the BacH and BacR concentrations at these locations (Table 3). Based on these comparisons, it can be concluded that the model predictions correspond with the field observations in Lake Rådasjön. However, more observations performed during different seasons would be beneficial for further validation of the model.

\section{Implications for MST}

The lack of knowledge on transport mechanisms and the decay processes in the environment limits direct quantification of fecal sources based on MST data alone. In another study, this limitation was addressed by linking catchment information to MST: fecal pollution source profile was used to generate a hypothesis about the dominant sources of pollution in the catchment; the sampling design and the selection of the appropriate MST tools were based on this hypothesis. ${ }^{12}$ In the present study, the fate and transport modeling was used to describe transport and decay processes in the water source and thus to address this limitation.

The presented modeling approach based on experimental decay data is a promising tool for the evaluation of genetic marker transport in a drinking water source. The hydrodynamic and microbiological model provides an estimate of the contribution from each fecal pollution site to the total concentration of Bacteroidales genetic markers at the raw water intake. Therefore, this modeling approach can be used in combination with MST for the identification and quantification of microbial pollution sources. This information can provide the basis for remediation measures and drinking water management in the context of waterborne disease outbreak prevention.

\section{Acknowledgements}

This research was mainly funded by the Swedish Water and Wastewater Association (SWWA) and the Graduate School on Environment and Health at Chalmers University of Technology and the University of Gothenburg, Sweden. The analyses for fecal indicator 
bacteria and somatic coliphages were partly funded by the city of Gothenburg and the EU project VISK (Interreg IV A program). We would like to express our gratitude to the members of the Rådasjön project management group for valuable support and input: Inger Kjellberg (Gothenburg Water); Reine Rohman, Dennis Yhr and Stefan Jonsson (Mölndal Water Works); Cecilia Wennberg, Anna Karlsson and Charlotte Borell Lövstedt (DHI); and Lars-Ove Sörman (Chalmers University of Technology). Special thanks are due to Niels Markwat for his help with the statistical analyses. We would also like to thank the three anonymous reviewers, whose comments helped to significantly improve the article.

\section{Supporting Information Available}

Supporting Information includes a description of the hydrodynamic model of Lake Rådasjön (including Table S1 and Figures S1 and S2), as well as Tables S2, S3 and S4. This information is available free of charge via the Internet at http://pubs.acs.org/ 


\section{References}

(1) Hrudey, S. E.; Hrudey, E. J. Safe drinking water: Lessons from recent outbreaks in affluent nations. IWA Publishing: London, 2004.

(2) Field, K. G.; Samadpour, M. Fecal source tracking, the indicator paradigm, and managing water quality. Water Res. 2007, 41 (16), 3517-3538.

(3) Reischer, G. H.; Kasper, D. C.; Steinborn, R.; Mach, R. L.; Farnleitner, A. H. Quantitative PCR method for sensitive detection of ruminant fecal pollution in freshwater and evaluation of this method in alpine karstic regions. Appl. Environ. Microbiol. 2006, 72 (8), 5610-5614.

(4) Reischer, G. H.; Kasper, D. C.; Steinborn, R.; Farnleitner, A. H.; Mach, R. L. A quantitative real-time PCR assay for the highly sensitive and specific detection of human faecal influence in spring water from a large alpine catchment area. Lett. Appl. Microbiol. 2007, 44 (4), 351-356.

(5) Converse, R. R.; Blackwood, A. D.; Kirs, M.; Griffith, J. F.; Noble, R. T. Rapid QPCR-based assay for fecal Bacteroides spp. as a tool for assessing fecal contamination in recreational waters. Water Res. 2009, 43 (19), 4828-4837.

(6) Stricker, A. R.; Wilhartitz, I.; Farnleitner, A. H.; Mach, R. L. Development of a Scorpion probe-based real-time PCR for the sensitive quantification of Bacteroides sp. ribosomal DNA from human and cattle origin and evaluation in spring water matrices. Microbiol. Res. 2008, 163 (2), 140-7.

(7) Layton, A.; McKay, L.; Williams, D.; Garrett, V.; Gentry, R.; Sayler, G. Development of Bacteroides 16S rRNA gene TaqMan-based real-time PCR assays for estimation of total, human, and bovine fecal pollution in water. Appl. Environ. Microbiol. 2006, 72 (6), 4214-24.

(8) Kildare, B. J.; Leutenegger, C. M.; McSwain, B. S.; Bambic, D. G.; Rajal, V. B.; Wuertz, S. 16S rRNA-based assays for quantitative detection of universal, human-, cow-, and dog-specific fecal Bacteroidales: A Bayesian approach. Water Res. 2007, 41 (16), 37013715.

(9) Bernhard, A. E.; Field, K. G. A PCR assay to discriminate human and ruminate feces on the basis of host differences in Bacteroides-Prevotella genes encoding 16S rRNA. Appl. Environ. Microbiol. 2000, 66, 4571-4574.

(10) Stapleton, C. M.; Kay, D.; Wyer, M. D.; Davies, C.; Watkins, J.; Kay, C.; Mcdonald, A. T.; Porter, J.; Gawler, A. Evaluating the operational utility of a Bacteroidales quantitative PCR-based MST approach in determining the source of faecal indicator organisms at a UK bathing water. Water Res. 2009, 43 (19), 4888-4899.

(11) Gourmelon, M.; Caprais, M. P.; Mieszkin, S.; Marti, R.; Wéry, N.; Jardé, E.; Derrien, M.; Jadas-Hécart, A.; Communal, P. Y.; Jaffrezic, A.; Pourcher, A. M. Development of microbial and chemical MST tools to identify the origin of the faecal pollution in bathing and shellfish harvesting waters in France. Water Res. 2010, 44 (16), 4812-4824.

(12) Reischer, G. H.; Kollanur, D.; Vierheilig, J.; Wehrspaun, C.; MacH, R. L.; Sommer, R.; Stadler, H.; Farnleitner, A. H. Hypothesis-driven approach for the identification of fecal pollution sources in water resources. Environ. Sci. Technol. 2011, 45 (9), 4038-4045.

(13) Walters, S. P.; Gannon, V. P. J.; Field, K. G. Detection of Bacteroidales fecal indicators and the zoonotic pathogens E. coli 0157:H7, salmonella, and campylobacter in river water. Environ. Sci. Technol. 2007, 41 (6), 1856-62.

(14) Fremaux, B.; Gritzfeld, J.; Boa, T.; Yost, C. K. Evaluation of host-specific Bacteroidales 16S rRNA gene markers as a complementary tool for detecting fecal pollution in a prairie watershed. Water Res. 2009, 43 (19), 4838-49. 
(15) Savichtcheva, O.; Okayama, N.; Okabe, S. Relationships between Bacteroides $16 \mathrm{~S}$ rRNA genetic markers and presence of bacterial enteric pathogens and conventional fecal indicators. Water Res. 2007, 41 (16), 3615-3628.

(16) Roslev, P.; Bukh, A. S. State of the art molecular markers for fecal pollution source tracking in water. Appl. Microbiol. Biotechnol. 2011, 89 (5), 1341-1355.

(17) Robertson, L. J.; Hermansen, L.; Gjerde, B. K.; Strand, E.; Alvsvåg, J. O.; Langeland, $\mathrm{N}$. Application of genotyping during an extensive outbreak of waterborne giardiasis in Bergen, Norway, during autumn and winter 2004. Appl. Environ. Microbiol. 2006, 72 (3), 2212-2217.

(18) Hipsey, M. R.; Antenucci, J. P.; Brookes, J. D. A generic, process-based model of microbial pollution in aquatic systems. Water Resour. Res. 2008, 44 (7).

(19) Liu, L.; Phanikumar, M. S.; Molloy, S. L.; Whitman, R. L.; Shively, D. A.; Nevers, M. B.; Schwab, D. J.; Rose, J. B. Modeling the transport and inactivation of E. coli and enterococci in the near-shore region of Lake Michigan. Environ. Sci. Technol. 2006, 40 (16), 5022-5028.

(20) Connolly, J. P.; Blumberg, A. F.; Quadrini, J. D. Modeling fate of pathogenic organisms in coastal waters of Oahu, Hawaii. J. Environ. Eng. 1999, 125 (5), 398-406.

(21) Kim, G.; Hur, J. Mortality rates of pathogen indicator microorganisms discharged from point and non-point sources in an urban area. J. Environ. Sci. (China) 2010, 22 (6), 929-33.

(22) Noble, R. T.; Lee, I. M.; Schiff, K. C. Inactivation of indicator microorganisms from various sources of faecal contamination in seawater and freshwater. J. Appl. Microbiol. 2004, 96 (3), 464-472.

(23) Davies, C. M.; Evison, L. M. Sunlight and the survival of enteric bacteria in natural waters. J. Appl. Bacteriol. 1991, 70 (3), 265-274.

(24) Crane, S. R.; Moore, J. A. Modeling Enteric Bacterial Die-Off - a Review. Water Air Soil Poll. 1986, 27 (3-4), 411-439.

(25) Bell, A.; Layton, A. C.; McKay, L.; Williams, D.; Gentry, R.; Sayler, G. S. Factors influencing the persistence of fecal Bacteroides in stream water. J. Environ. Qual. 2009, 38 (3), 1224-1232.

(26) Dick, L. K.; Stelzer, E. A.; Bertke, E. E.; Fong, D. L.; Stoeckel, D. M. Relative decay of bacteroidales microbial source tracking markers and cultivated escherichia coli in freshwater microcosms. Appl. Environ. Microbiol. 2010, 76 (10), 3255-3262.

(27) Okabe, S.; Shimazu, Y. Persistence of host-specific Bacteroides-Prevotella 16S rRNA genetic markers in environmental waters: effects of temperature and salinity. Appl. Microbiol. Biotechnol. 2007, 76 (4), 935-44.

(28) Walters, S. P.; Field, K. G. Survival and persistence of human and ruminantspecific faecal Bacteroidales in freshwater microcosms. Environ. Microbiol. 2009, 11 (6), 1410-1421.

(29) ISO. Water Quality - Detection and enumeration of intestinal enterococci Part 2: Membrane filtration method, ISO 7899-2; International Organization for Standardization: Geneva, Switzerland, 2000.

(30) ISO. Water Quality - Detection and enumeration of bacteriophages - Part 2: Enumeration of somatic coliphages, ISO 10705-2; International Organization for Standardization: Geneva, Switzerland, 2000.

(31) Griffiths, R. I.; Whiteley, A. S.; O'Donnell, A. G.; Bailey, M. J. Rapid method for coextraction of DNA and RNA from natural environments for analysis of ribosomal DNAand rRNA-based microbial community composition. Appl. Environ. Microbiol. 2000, 66 (12), 5488-91. 
(32) Chick, H.; Martin, C. J. The Principles Involved in the Standardisation of Disinfectants and the Influence of Organic Matter upon Germicidal Value. J. Hyg. 1908, 8 (5), 654-697.

(33) DHI. MIKE 3 Estuarine and Coastal Hydraulics and Oceanography, Short Description; DHI Water \& Environment: Horsholm, 2009; http://mikebydhi.com/ /media/Microsite_MIKEbyDHI/Publications/PDF/M3_ShortDescr.ash $\underline{\mathrm{x}}$.

(34) DHI. MIKE 21/3 Ecological Modelling: MIKE21/3 ECO Lab FM Short Description; DHI Water \& Environment: Horsholm, 2004; http://www.dhigroup.com/upload/dhisoftwarearchive/shortdescriptions/marine/MIKE213_FM EL_Short_Description.pdf.

(35) Mancini, J. L. Numerical estimates of coliform mortality rates under various conditions. J. Water Pollut. Control Fed. 1978, 50 (11), 2477-2484.

(36) Medema, G. J.; Bahar, M.; Schets, F. M. Survival of Cryptosporidium parvum, Escherichia coli, faecal enterococci and Clostridium perfringens in river water: Influence of temperature and autochthonous microorganisms. Water Sci. Technol. 1997, 35 (11-12), 249252.

(37) Ballesté, E.; Blanch, A. R. Persistence of Bacteroides species populations in a river as measured by molecular and culture techniques. Appl. Environ. Microbiol. 2010, 76 (22), 7608-7616.

(38) Bae, S.; Wuertz, S. Rapid decay of host-specific fecal Bacteroidales cells in seawater as measured by quantitative PCR with propidium monoazide. Water Res. 2009, 43 (19), 4850-4859.

(39) Boehm, A. B.; Yamahara, K. M.; Love, D. C.; Peterson, B. M.; McNeill, K.; Nelson, K. L. Covariation and photoinactivation of traditional and novel indicator organisms and human viruses at a sewage-impacted marine beach. Environ. Sci. Technol. 2009, 43 (21), 8046-52.

(40) Walters, S. P.; Yamahara, K. M.; Boehm, A. B. Persistence of nucleic acid markers of health-relevant organisms in seawater microcosms: Implications for their use in assessing risk in recreational waters. Water Res. 2009, 43 (19), 4929-4939.

(41) Pernthaler, J. Predation on prokaryotes in the water column and its ecological implications. Nat. Rev. Microbiol. 2005, 3 (7), 537-46.

(42) Matsui, K.; Honjo, M.; Kawabata, Z. Estimation of the fate of dissolved DNA in thermally stratified lake water from the stability of exogenous plasmid DNA. Aquat. Microb. Ecol. 2001, 26 (1), 95-102.

(43) Obiri-Danso, K.; Paul, N.; Jones, K. The effects of UVB and temperature on the survival of natural populations and pure cultures of Campylobacter jejuni, Camp. coli, Camp. lari and urease-positive thermophilic campylobacters (UPTC) in surface waters. $J$. Appl. Microbiol. 2001, 90 (2), 256-67.

(44) Allwood, P. B.; Malik, Y. S.; Hedberg, C. W.; Goyal, S. M. Survival of Fspecific RNA coliphage, feline calicivirus, and Escherichia coli in water: A comparative study. Appl. Environ. Microbiol. 2003, 69 (9), 5707-5710. 


\section{Tables}

Table 1. Concentrations of BacH and BacR markers in the pollution sources around Lake Rådasjön measured during the year 2008

\begin{tabular}{lllll}
\hline Indicator & Site & No of samples ${ }^{a}$ & \multicolumn{2}{l}{ Concentration, ME/100 mL } \\
& & & Median & Max \\
\hline BacH & 3 & $7(7)$ & $1.6 \times 10^{5}$ & $1.3 \times 10^{6}$ \\
& 7 & $5(5)$ & $5.8 \times 10^{4}$ & $3.1 \times 10^{6}$ \\
& $\mathrm{P}$ & $4(4)$ & $7.6 \times 10^{8} \mathrm{~b}$ & $1.3 \times 10^{9} \mathrm{~b}$ \\
BacR & 17 & $6(6)$ & $3.7 \times 10^{5}$ & $2.3 \times 10^{7}$ \\
\hline
\end{tabular}

${ }^{a}$ Number of positive samples is shown in brackets.

${ }^{\mathrm{b}}$ Measured concentrations of $\mathrm{BacH}$ in wastewater samples from the pumping station where emergency sewer overflows occur. During emergency sewer overflows a mixture of stormwater and wastewater is discharged into the lake, therefore, a dilution factor 10 was assumed to provide input data for the simulations. 
Table 2. Decay rates and persistence of fecal indicators calculated using the obtained experimental data

\begin{tabular}{|c|c|c|c|c|c|}
\hline Organism & Regime & Season & $\begin{array}{l}\text { C(0) }{ }^{\mathrm{a}}, \\
\text { No/100 mL }\end{array}$ & $\begin{array}{l}\text { k-value }{ }^{b} \text {, } \\
\text { /day }\end{array}$ & $\begin{array}{l}\text { T90-value }{ }^{\mathrm{C}} \text {, } \\
\text { days }\end{array}$ \\
\hline \multirow[t]{6}{*}{$\mathrm{BacH}$} & \multirow[t]{3}{*}{ Light } & March & $1.3 \times 10^{8}$ & $-0.30(-0.44 ;-0.17)$ & $7.6(5.3 ; 13.9)$ \\
\hline & & August & $6.7 \times 10^{7}$ & $-1.00(-1.44 ;-0.56)$ & $2.3(1.6 ; 4.1)$ \\
\hline & & November & $3.6 \times 10^{7}$ & $-0.45^{\mathrm{d}}$ & - \\
\hline & \multirow[t]{3}{*}{ Dark } & March & $1.2 \times 10^{8}$ & $-0.33(-0.48 ;-0.19)$ & $6.9(4.8 ; 12.2)$ \\
\hline & & August & $2.9 \times 10^{7}$ & $-1.76(-2.04 ;-0.48)$ & $1.3(0.8 ; 4.8)$ \\
\hline & & November & $3.1 \times 10^{8}$ & $-0.02^{\mathrm{d}}$ & - \\
\hline \multirow[t]{6}{*}{ BacR } & \multirow[t]{3}{*}{ Light } & March & $9.1 \times 10^{8}$ & $-0.34(-0.50 ;-0.19)$ & $6.7(4.6 ; 12.2)$ \\
\hline & & August & $4.1 \times 10^{8}$ & $-1.61(-2.23 ;-1.00)$ & $1.4(1.0 ; 2.3)$ \\
\hline & & November & $4.1 \times 10^{8}$ & $-0.24(-0.39 ;-0.10)$ & $9.5(5.9 ; 23.5)$ \\
\hline & \multirow[t]{3}{*}{ Dark } & March & $1.0 \times 10^{9}$ & $-0.37(-0.50 ;-0.24)$ & $6.2(4.6 ; 9.4)$ \\
\hline & & August & $5.1 \times 10^{8}$ & $-1.11(-1.56 ;-0.66)$ & $2.1(1.5 ; 3.5)$ \\
\hline & & November & $6.2 \times 10^{8}$ & $-0.22(-0.37 ;-0.07)$ & $10.6(6.3 ; 32.0)$ \\
\hline \multirow{6}{*}{$\begin{array}{l}\text { Total } \\
\text { coliforms }\end{array}$} & \multirow[t]{3}{*}{ Light } & March & $9.8 \times 10^{5}$ & $-0.20(-0.29 ;-0.11)$ & $11.6(7.9 ; 21.7)$ \\
\hline & & August & $2.0 \times 10^{6}$ & $-0.67(-0.80 ;-0.54)$ & $3.4(2.9 ; 4.3)$ \\
\hline & & November & $7.4 \times 10^{5}$ & $-0.29(-0.44 ;-0.14)$ & $8.0(5.3 ; 16.8)$ \\
\hline & \multirow[t]{3}{*}{ Dark } & March & $7.7 \times 10^{5}$ & $-0.24(-0.38 ;-0.09)$ & $9.7(6.0 ; 25.0)$ \\
\hline & & August & $1.6 \times 10^{6}$ & $-0.28(-0.46 ;-0.09)$ & $8.3(5.0 ; 25.0)$ \\
\hline & & November & $1.0 \times 10^{6}$ & $-0.33(-0.45 ;-0.20)$ & $7.1(5.1 ; 11.7)$ \\
\hline \multirow[t]{6}{*}{ E. coli } & \multirow[t]{3}{*}{ Light } & March & $3.1 \times 10^{5}$ & $-0.55(-0.69 ;-0.42)$ & $4.2(3.3 ; 5.5)$ \\
\hline & & August & $1.4 \times 10^{6}$ & $-1.03(-1.28 ;-0.78)$ & $2.2(1.8 ; 3.0)$ \\
\hline & & November & $6.9 \times 10^{5}$ & $-0.35(-0.53 ;-0.17)$ & $6.5(4.3 ; 13.2)$ \\
\hline & \multirow[t]{3}{*}{ Dark } & March & $2.4 \times 10^{5}$ & $-0.50(-0.72 ;-0.28)$ & $4.6(3.2 ; 8.2)$ \\
\hline & & August & $1.3 \times 10^{6}$ & $-0.61(-0.86 ;-0.36)$ & $3.8(2.7 ; 6.4)$ \\
\hline & & November & $1.0 \times 10^{6}$ & $-0.39(-0.56 ;-0.22)$ & $5.9(4.1 ; 10.3)$ \\
\hline \multirow{6}{*}{$\begin{array}{l}\text { Intestinal } \\
\text { enterococci }\end{array}$} & \multirow[t]{3}{*}{ Light } & March & $4.6 \times 10^{3}$ & $-0.82(-1.04 ;-0.60)$ & $2.8(2.2 ; 3.9)$ \\
\hline & & August & $9.1 \times 10^{2}$ & $-0.99^{\mathrm{d}}$ & - \\
\hline & & November & $3.2 \times 10^{3}$ & $-0.33(-0.55 ;-0.12)$ & $6.9(4.2 ; 19.5)$ \\
\hline & \multirow[t]{3}{*}{ Dark } & March & $5.0 \times 10^{3}$ & $-0.36(-0.48 ;-0.24)$ & $6.4(4.8 ; 9.4)$ \\
\hline & & August & $6.4 \times 10^{3}$ & $-0.69(-1.11 ;-0.27)$ & $3.3(2.1 ; 8.5)$ \\
\hline & & November & $3.5 \times 10^{3}$ & $-0.22(-0.39 ;-0.05)$ & $10.4(5.9 ; 47.0)$ \\
\hline \multirow{6}{*}{$\begin{array}{l}\text { Somatic } \\
\text { coliphages }\end{array}$} & \multirow[t]{3}{*}{ Light } & March & $4.9 \times 10^{2}$ & $-0.16(-0.20 ;-0.13)$ & $14.1(11.7 ; 17.8)$ \\
\hline & & August & $4.4 \times 10^{2}$ & $-0.45(-0.55 ;-0.35)$ & $5.1(4.2 ; 6.6)$ \\
\hline & & November & $3.7 \times 10^{1}$ & $-0.10^{\mathrm{d}}$ & - \\
\hline & \multirow[t]{3}{*}{ Dark } & March & $4.9 \times 10^{2}$ & $-0.11(-0.19 ;-0.03)$ & $21.3(12.4 ; 76.8)$ \\
\hline & & August & $3.9 \times 10^{2}$ & $-0.31(-0.51 ;-0.10)$ & $7.5(4.5 ; 23.5)$ \\
\hline & & November & $2.0 \times 10^{1}$ & $-0.16(-0.30 ;-0.02)$ & $14.7(7.8 ; 135.4)$ \\
\hline
\end{tabular}

\footnotetext{
${ }^{\mathrm{a}}$ Initial concentrations $(\mathrm{C}(0))$ were detected in the microcosms on day 0 .

${ }^{\mathrm{b}}$ Decay rates (k-values) were calculated according to Equation 1; $95 \%$ confidence intervals are shown in brackets.

${ }^{\mathrm{c}}$ Persistence (T90-values) was defined as time for a $90 \%$ reduction and calculated according to Equation 2.

${ }^{\mathrm{d}} \mathrm{p}>0.05$
} 


\section{List of figure captions}

Figure 1. Map of Lake Rådasjön and sources of microbial pollution from humans (sites 3, 7, emergency sewer overflow - P) and cattle (site 17). The location of the raw water intakes is indicated with a blue dot. Lake water for construction of the microcosms was collected at site V. Inflow to and outflow from the lake are shown by arrows.

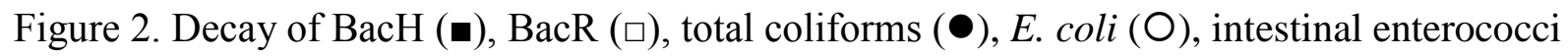
$(\boldsymbol{\Delta})$ and somatic coliphages $(\Delta)$ in trials performed in March (A and B), August (C and D) and November ( $\mathrm{E}$ and $\mathrm{F}$ ) under daylight exposure and in darkness (left and right figures). Microbial concentrations were plotted on the natural logarithmic scale according to Equation 1. The variability in the BacH and BacR measurements was analyzed on days 1 and 7 in both microcosms in the March trial; the standard deviations for the BacH and BacR measurements were below 35 and $21 \%$ of the mean, respectively. No error bars were shown in the figure as these would be too small for the scale of the figure.

Figure 3. Simulated concentrations at which Bacteroidales genetic markers (BacH/BacR) from the different fecal pollution sources reached the raw water intakes at 8 and $15 \mathrm{~m}$ depths under conditions of different months and wind directions (southwest SW and southeast SE). Median and maximum observed concentrations of BacH/BacR in the discharges from pollution sources were used as input data for the simulations of normal and worst case scenarios, respectively. 


\section{Figures}

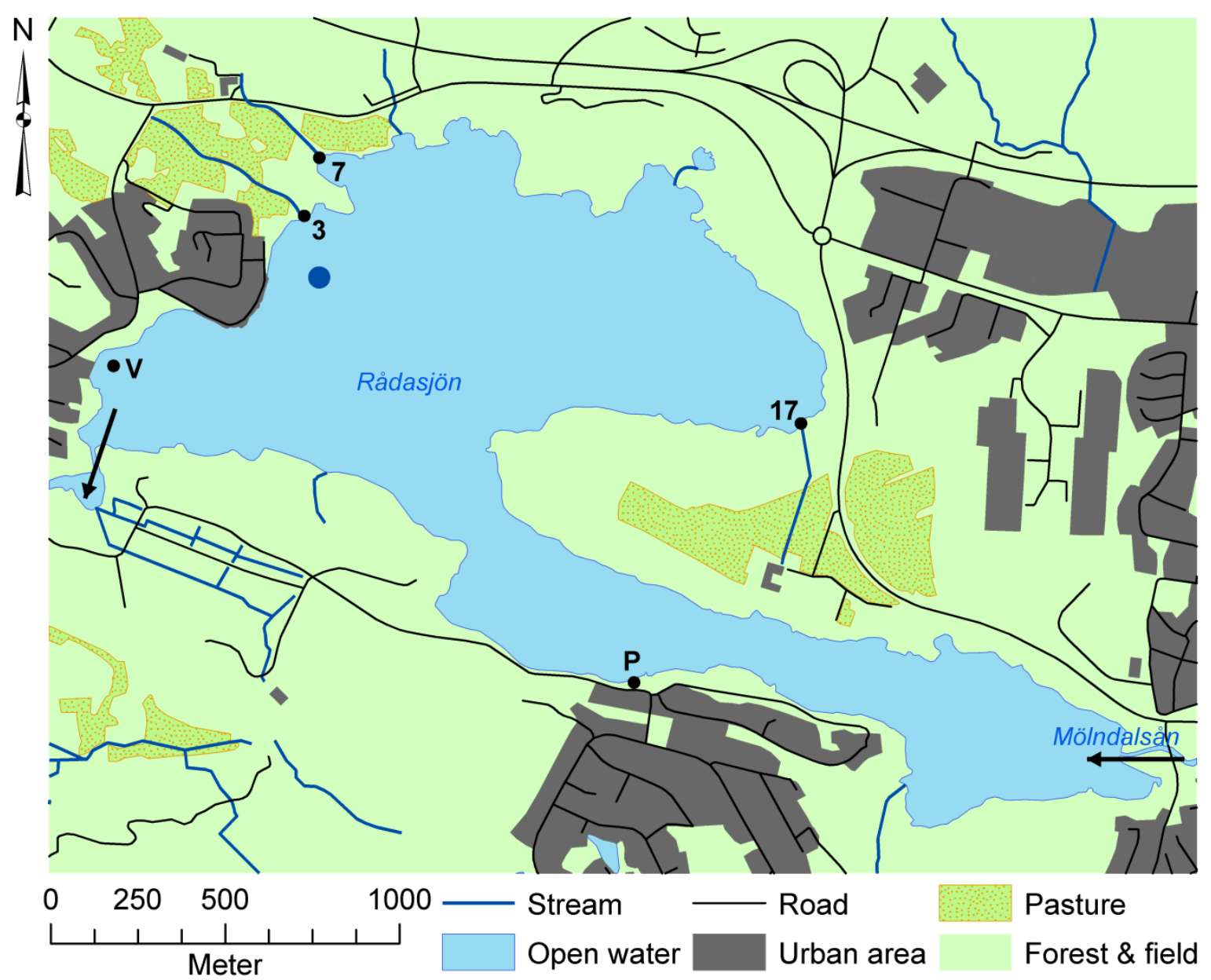

Figure 1. Map of Lake Rådasjön and sources of microbial pollution from humans (sites 3, 7, emergency sewer overflow - P) and cattle (site 17). The location of the raw water intakes is indicated with a blue dot. Lake water for construction of the microcosms was collected at site $\mathrm{V}$. Inflow to and outflow from the lake are shown by arrows. 
A

March, light

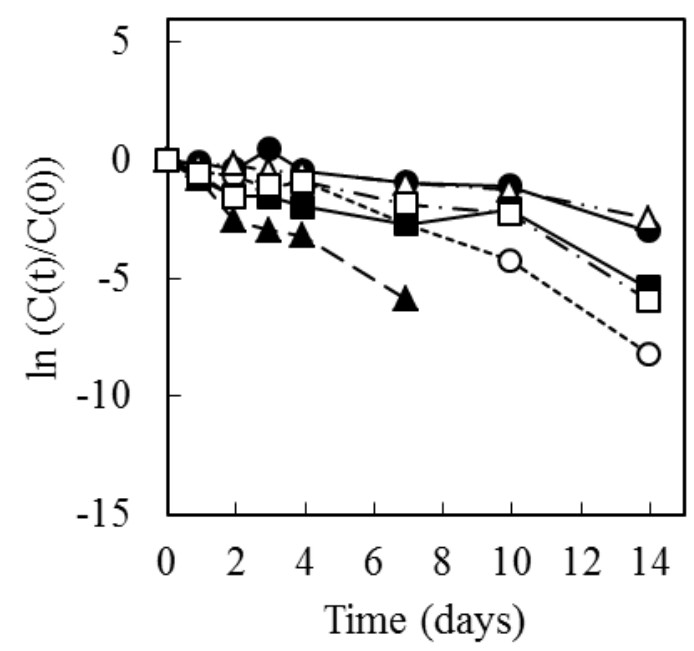

C

August, light

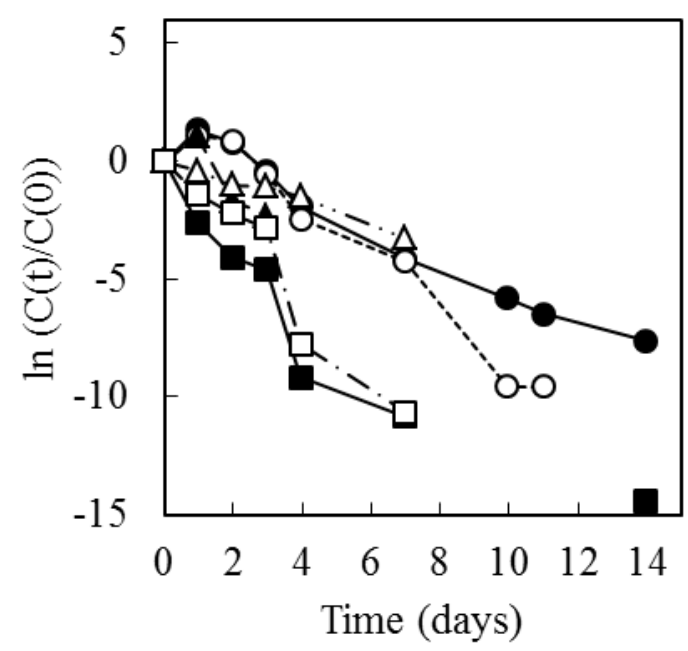

E

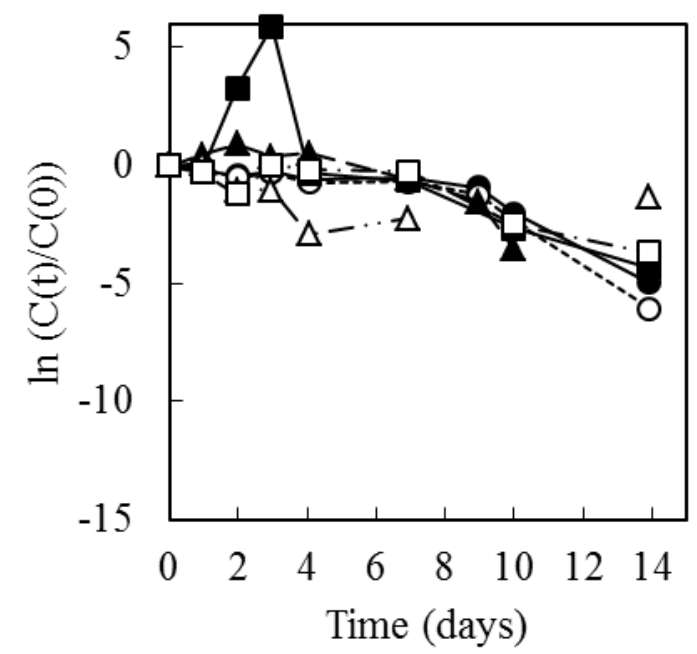

B March, dark

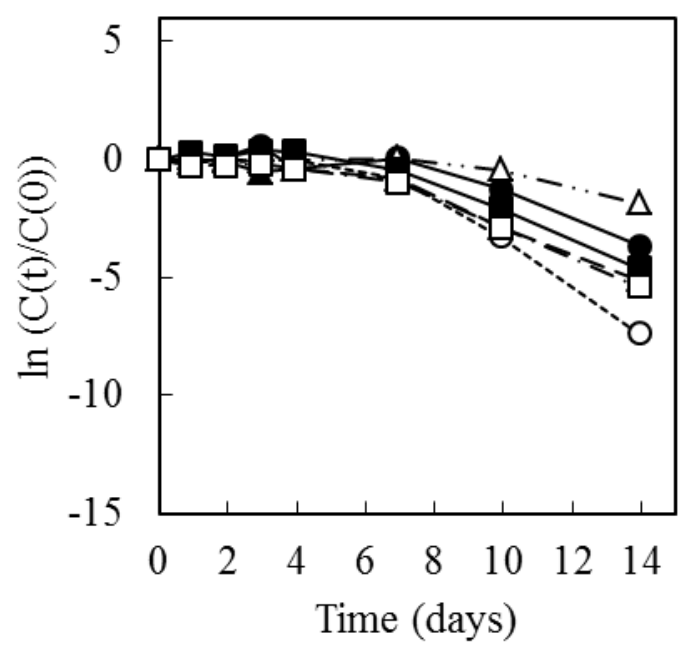

D August, dark

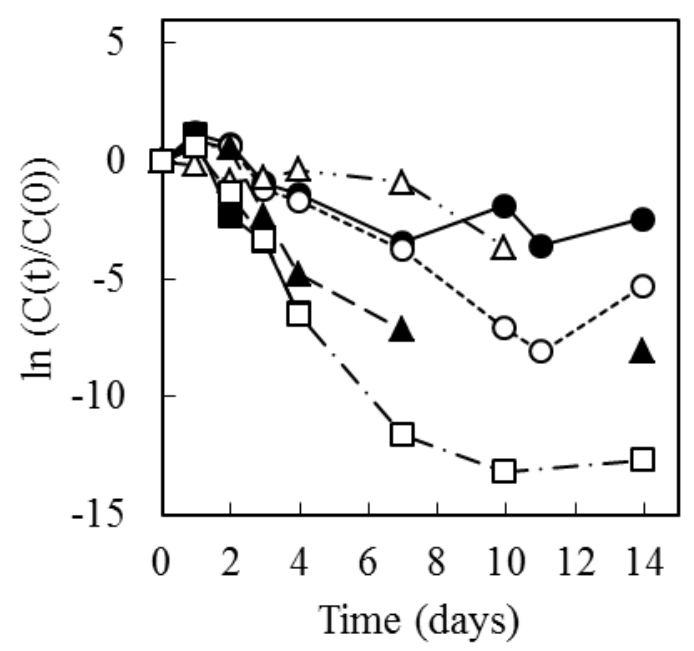

F November, dark

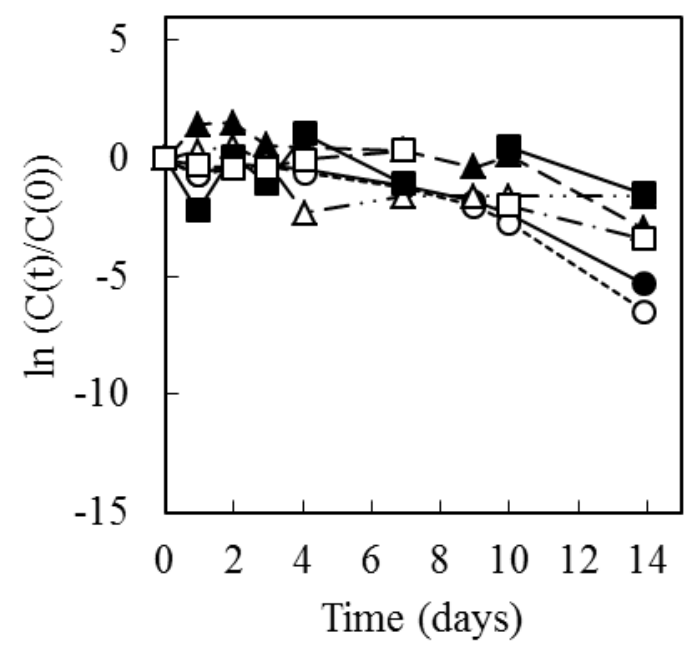




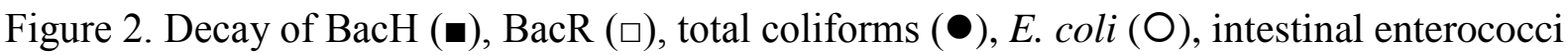
$(\Delta)$ and somatic coliphages $(\Delta)$ in trials performed in March (A and B), August (C and D) and November ( $\mathrm{E}$ and $\mathrm{F}$ ) under daylight exposure and in darkness (left and right figures).

Microbial concentrations were plotted on the natural logarithmic scale according to Equation 1. The variability in the BacH and BacR measurements was analyzed on days 1 and 7 in both microcosms in the March trial; the standard deviations for the BacH and BacR measurements were below 35 and $21 \%$ of the mean, respectively. No error bars were shown in the figure as these would be too small for the scale of the figure. 


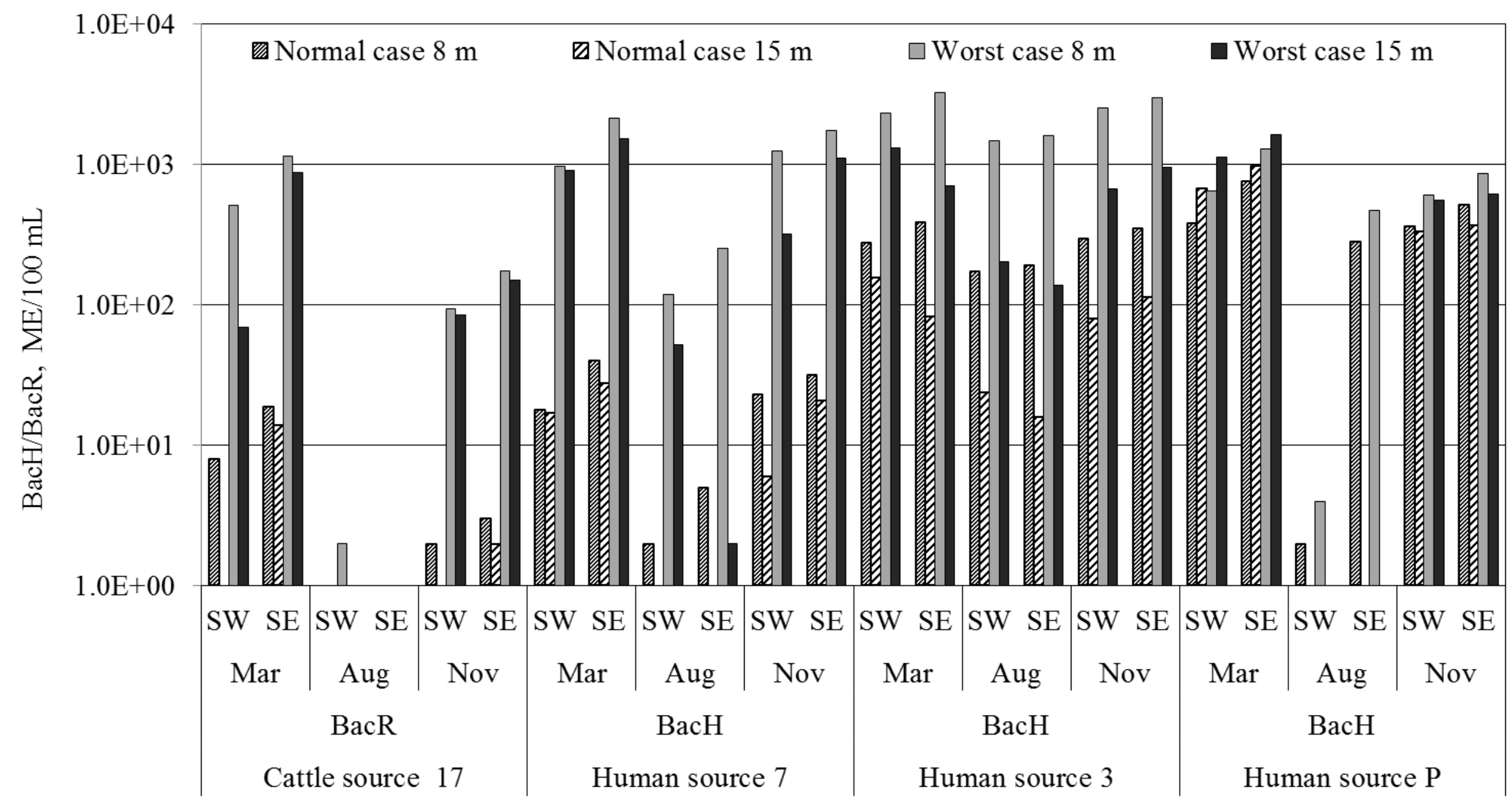


Figure 3. Simulated concentrations at which Bacteroidales genetic markers (BacH/BacR) from the different fecal pollution sources reached the raw water intakes at 8 and $15 \mathrm{~m}$ depths under conditions of different months and wind directions (southwest SW and southeast SE). Median and maximum observed concentrations of $\mathrm{BacH} / \mathrm{BacR}$ in the discharges from pollution sources were used as input data for the simulations of normal and worst case scenarios, respectively. 